Ensino de História/

History Teaching 


\section{A história ensinada sob o império da memória: questões de História da disciplina}

Maria Aparecida Leopoldino Tursi TOLEDO ${ }^{1}$

R E SU M 0: Este trabalho trata de uma reflexão acerca da história ensinada nas séries iniciais do ensino fundamental na perspectiva da $H$ istória das disciplinas. 0 texto procura mostrar a contribuição das atuais pesquisas sobre História e M emória para a compreensão da trajetória desta disciplina escolar a partir do discernimento de ambos os termos no trato de seus percursos disciplinares. Registra que a história ensinada, principalmente nas séries iniciais, esteve dominantemente sob o império da memória não apenas porque havia a compreensão de queo ensino de História se fazia pela memorização de datas e vultos nacionais, mas porque foi a partir do recurso metodológico e historiográfico do século XIX que a História se tornou um meio importante para dispor da memória e converter-se em História nacional.

Pa Lav r A S- C h ave: H istória das Disciplinas; História ensinada; História e memória.

Os atuais estudos sobre a relação História e Memória partem do suposto de que a visão tradicional desta relação, "na qual a memória reflete o que aconteceu na verdade e a história reflete a memória, parece hoje demasiado simples"2 $\mathrm{N}$ a verdade, tanto a História quanto a memória passaram a revelar-se cada vez mais complexas, como afirma Burke:

Lembrar o passado e escrever sobre ele não mais parecem atividades inocentes que outrora sejul gava que fossem. Nem as memórias nem as histórias parecem mais ser objetivas. N os dois casos, os historiadores aprendem a levar em conta a seleção consciente ou inconsciente, a interpretação e a distorção. N os dois casos, passam a ver o processo de sel eção, interpretação edistorção como condicionado, ou pelo menosinfluenciado, por grupos sociais. Não é obra de indivíduos isolados. ${ }^{3}$ 
A partir de tal constatação, o tema da memória passa, no século $X X$, a ser estudado com maior dedicação por historiadores contemporâneos, confiantes na comprovação de sua dimensão social. ${ }^{4}$

A contribuição de Pierre Nora (1993) e Jacques Le Goff (1996), no discernimento da relação História e Memória, trouxe para o campo da investigação sobre o ensino de H istória e da História ensinada, mudanças significativas no trato dos percursos disciplinares escolares e acadê micos, fundamental menteno que se refereà prática eà discussão sobrea História ensinada. Vejamos por quê.

Para Nora, memória e História não são sinônimos, mas se opõem. Nas suas palavras:

A memória é a vida, sempre carregada por grupos vivos e, nesse sentido, ela está em permanente evolução, aberta à dialética da lembrança e do esquecimento, inconsciente de suas deformações sucessivas, vulneráveis a todos os usos e manipulações, suscetível de longas latências de repentinas revitalizações. A H istória é a reconstrução sempre problemática e incompleta do que não existe mais. A memória é um fenômeno sempre atual, um elo vivido no eterno presente; a história, uma representação do passado. $^{5}$

Na concepção desse autor, a História se oporia à memória naquilo que ela tem de mais significativo: 0 absoluto. Pois, enquanto a memória se enraíza no saber absoluto, a H istória "só seliga às continuidades temporais, às evoluções e às relações das coisas". D esta maneira, a memória "é sempre suspeita para a história".

Le Goff indica que a memória tem como propriedade conservar certas informações, que não são ingênuas, mas se fazem er efazem a partir de interesses de grupos. Estudando o desenvolvimento da memória desde a Antigüidade, el e mostra quea

[...] evolução das sociedades na segunda metade do século XX clarifica a importância do papel que a memória coletiva desempenha. Exorbitando a história como ciência e como culto público, ao mesmo tempo a montagem enquanto reservatório (móvel) da história, rico em arquivos e em documentos/monumentos, e o aval, eco sonoro (e vivo) do trabalho histórico, a memória coletiva faz parte das grandes questões das sociedades 
desenvolvidas e das sociedades em vias de desenvolvimento, das classes dominantes e das classes dominadas, lutando todas pelo poder ou pela vida, pela sobrevivência e pela promoção. ${ }^{6}$

Tem-se, assim, um dos sinais mais tangíveis da diferença entre história e memória que faz pensar, de imediato, nas reflexões didáticas sobreo ensino da H istória. Isto porque, nesteterreno, vinham-sedelineando nesta análise dois aspectos fundamentais: um que cerca a atenção em denunciar a redução do ensino da História "a uma seqüência de fatos, marcos, frases ou idéias prontas", e outro que critica o ensino pela "imposição do conteúdo à memorização e redução do aluno a ouvinte".7

Sem uma investigação ou conhecimento do debate historiográfico sobre a relação História e Memória, tais críticas, embora pertinentes, reduziram-se a sinalizar o fato de que o ensino de H istória deveria superar a memorização dos conteúdos e suas implicações na prática educativa do ensino desta disciplina. Essa situação resultou no entendimento da memória percebida especificamente sob a dimensão cognitiva, não tocando no discernimento deH istória e memória como conceitos historiográficos.

Por isso, um dos impactos mais positivos registrados com a publicação desses autores éa demarcação da diferença entre H istória ememória. Isto porque, certamente, tal discernimento conceitual possibilitará caminhar para além do debate sobre o ensino percebido exclusivamente nos termos anteriormente descritos. 0 que significa dizer que possivelmente permitirá avançar em direção à análise da perspectiva historiográfica que envolve a questão do ensino e da História ensinada.

N esse sentido, no que tange às relações entre História e seu ensino, esta abordagem é contributiva, pois obrigará a refletir sobre a H istória no confronto com a memória e tornar mais claras as tradições historiográficas, culturais, acadêmicas e escolares que historicamente as envolve. Além disso, ensinará a pensar em todos esses campos a partir de uma "história de disciplina". Ou seja, de um processo de institucionalização de práticase profissionalização dos quadros professorais, que pode traduzir contribuições relevantes para a compreensão dos perfis adotados pela disciplina que compõe os currículos escolares e acadêmicos.

I sso permite, finalmente, colaborar com a crítica do discurso pedagógico que talvez, pelo imediatismo da análise, desconheça ou descon- 
sidere a fértil discussão sobre o modo como historicamente essa disciplina escolar se firma e ganha legitimidade.

Por esses motivos, para o campo da história da disciplina esta abordagem émuito salutar, pois permiteo reconhecimento de quea $\mathrm{H}$ istória ensinada fundamentalmente nas séries iniciais esteve dominantemente sob o império da memória, não apenas porque havia a compreensão de que o ensino de História se fazia pela memorização de datas, fatos e vultosheróicos, mas porque foi a partir do recurso metodológico ehistoriográfico do século XIX quea história se tornou um meio importantepara dispor da memória e converter-se em História nacional.

A essas considerações teórico-metodológicas acrescento uma de grande importância: o fato de que quem trabalha com conteúdos de história nessas séries são profissionais formados nos cursos de Pedagogia, que nem sempre tomam contato com a produção historiográfica e em geral limitam-se ao ensino dos conteúdos indiciados nos livros didáticos.

Junto com essas considerações preliminares, reafirmo meu interesse em estudar a história que é ensinada nos ciclos iniciais do ensino fundamental e, neste caso, verificar a potencial idade deste estudo sobrea memória para a compreensão da forma que a $\mathrm{H}$ istória ensinada assume no século XIX.

Isso porque, como anteriormente mencionado, muitos trabalhos já se dedicaram em denunciar o uso da memória (memorização) dos conteúdos dehistória, tendo como argumento central quea memorização impede a reflexão da história como movimento de continuidade e descontinuidade. Centrados, no entanto, em uma perspectiva que, ao se falar em memória no ensino da H istória, a referência imediata é a memória entendida especificamente sob a perspectiva da cognição, tornouse lacunar a discussão teórico-metodológica sobre a relação História e memória na abordagem acima referida, embora no final dos anos 1980 já houvesse estudos que apontassem para essa relação. ${ }^{8}$

Acrescento, portanto, a essa discussão, a necessidade de demarcar, como historicamente determinada, a relação da $\mathrm{H}$ istória ensinada com a memória, seja coletiva, seja individual. Esse trajeto implica retomar os estudos sobre o nascimento da H istória como disciplina escolar e sua institucionalização como disciplina que ensina a História Pátria desde práticas sociais/educacionais dominantes, para entender como o ensino 
da História, em suas origens, toma o caminho da formação da memória nacional, explorando essa relação a partir dos nexos existentes entreeducação e sociedade.

Dessa maneira, inscrevo minha participação nesse debateque provém da investigação realizada sobre as origens da $\mathrm{H}$ istória como disciplina escolar na perspectiva da "História das disciplinas". 9 Perspectiva que possibilita visualizar o itinerário pelo qual a História passa em seu processo de constituição como disciplina escolar no conjunto dos diferentes saberes para, ao longo desse processo, firmar-se como campo de conhecimento escolar independente no interior da sociedadeque lhe dá sustentação.

Buscando esse trajeto, verifiquei que a História como disciplina escolar tem sua origem no ensino das humanidades dos colégios do Antigo Regime como parte dos estudos secundários. Segundo Chervel \& Compére (1999), o nome de humanidades, na origem, foi dado pelos jesuítas aos estudos intermediários entre os de gramática eos deretórica, uma denominação própria para aU niversidade de Paris, queseria adotada na França para os estudos secundários, nomeados também como estudos de poesia. Vale dizer que até ser introduzida como disciplina autônoma nos currículos escolares, a H istória esteve entre as Humanidades.

Estudando os saberes ensinados nos colégios jesuítas do século XVII, Bruter ${ }^{10}$ indica que não se pode reconhecer naquele período nenhuma das disciplinas escolares como conhecemos hoje, porque a finalidade do ensino humanista édiferente das finalidades cognitivas geralmente reconhecidas no ensino atualmente. Para ela, a organização dos estudos de humanidades manifesta-se claramente na finalidade retórica: ${ }^{11}$ a aprendizagem das línguas antigas, essencialmente o latim, e acessoriamente 0 grego.

Não existindo como matéria específica, com programas e horários próprios, a História estava entre as letras antigas através do estudo de erudição e obras de autores latinos e gregos. Associada à Geografia, era considerada um exemplo especial de conhecimento necessário ao homem virtuoso, tinha a tarefa de auxiliar na educação clássica, que consistia na "formação do espírito que tende a desenvolver um certo número de qualidades, ou seja, a clareza do pensamento eda expressão; o rigor no encadeamento das idéias e de proposições; 0 cuidado com a medida e 
o equilíbrio; a adequação mais justa possível da língua à idéia"12 $M$ as, considera Bruter: "A pedagogia humanista não visava somente fazer adquirir o domínio dos 'princípios' oratórios, ela procura sim fornecer mobilidade aos discursos e a guiar a vida." ${ }^{13}$

A História consistia, assim, em uma referência moral e religiosa para "orientar os espíritos de noção sobre o passado da Grécia e Roma através dos cursos de explicações de Cornelius N epos, Cícero, Tito Lívio, Salustio, Tácito, Tucidides, Demóstenes, Platão, Xénophon e outros autores gregose latinos", ${ }^{14}$ com o objetivo delevar o aluno a uma compreensão íntima do texto estudado, a uma explicação com detalhes minuciosos e a uma opinião global da obra. Assim, os conteúdos de história presentes nesses textos eram considerados importantes aos homens de letras, moralistas e políticos.

A partir do século XVIII, o monopólio intelectual dos jesuítas passou a ser condenado pelos parlamentares franceses que apresentavam projetos para a organização dos sistemas nacionais de ensino, nos quais se previa a autonomia da língua francesa e a crítica da centralidade no latim. ${ }^{15}$ Tal movimento de redefinição do projeto social europeu resultou na expulsão da Companhia de Jesus e provocou uma grande discussão sobre os sistemas nacionais de Educação na Europa. ${ }^{16}$

Vasculhando a literatura produzida, sobretudo na França, entre 0 final do século XIX e início do XX, como resultado do debate em torno da criação dos Sistemas Nacionais de Ensino, verifiquei que, mais que em qualquer outro país, foi na França que a discussão em torno da escola pública tomou proporções real mente significativas, lembrando ainda que foi "com a Revolução Francesa que os princípios de universalidade, gratuidade, laicidade e obrigatoriedade passaram a compor a escola pública como a concebemos hoje". ${ }^{17}$

Por isso, ao efetuar a investigação histórica da relação que se estabelece entreensino de História e memória, o farei a partir deum recorte de marcada importância para o debate sobre a História ensinada nas séries iniciais, que é o surgimento desta disciplina na França, no século XIX, no interior da origem da escola pública francesa. Nesse sentido, 0 trabalho pioneiro de Furet é relevante. ${ }^{18} \mathrm{Em}$ seu estudo sobre o "nascimento da história", encontrei alguns indícios de toda a tradição histórica que se desenvolveu na França com a constituição do ensino de História 
durante a III República francesa, que pode ser útil ao entendimento da transmissão escolar da memória coletiva através dos conteúdos históricos presentes nas escolas brasileiras, sem correr o risco de simplesmenteadequar à situação brasileira aquele modelo, mas buscar no modo como se apropria deleparao desempenho defunçõesquelhesão complementares.

A III República Francesa nascente assume por fim toda a herança nacional em nome do povo, porque ela própria é, finalmente, e quase ao fim de um século, a Revolução Francesa no poder: essa figura provisória, mas que vai revelar-se bastante duradoura, é constituída por um poder conservador que governa em nome dos val ores revolucionários. A partir deste momento a história já não constitui apenas uma matéria de ensino secundário ou superior, é também indispensável aos mais pequenos, cujo juízo e patriotismo devem ser formados cedo. ${ }^{19}$

Furet alerta para o fato de que, nesse momento, 0 ensino de História para a instrução primária, na França, nasceu sob o signo da Nação.

A preocupação com ea inclusão da H istória da França nos programas curriculares franceses designava a renovação do ensino como interesse da nação que, sob a autoridade republicana, indicava o caminho para o progresso, conforme assinala Hery: “(...) os republicanos desejavam fundar uma nova moral e uma nova unidade nacional, elivrar a sociedade das superstições e preconceitos na qual conservavam os religiosos".20

La Chalotais (1701-1785) ${ }^{21}$ traduz bem esse sentimento, nestas palavras:

0 ensino das leis divinas é assunto da Igreja, mas o ensino da moral é atributo do Estado [...]. Como se pode ter pensado que homens que não são vinculados ao Estado, que estão acostumados a colocar um religioso acima do chefe do Estado [...] seriam capazes de educar e instruir a juventude de um reino? [...] Assim, o ensino de todas as nações, esta porção da legislação que é a base e o fundamento dos Estados, permanece sob a direção imediata de um regime cujo centro se encontra para além dos Alpes, necessariamente inimigo das nossas leis. Queinconsequência e que escândal 0.22

Segundo Hery, a partir das leis constitucionais de 1875, reforça-se o sentimento nacional de que era preciso enraizar-se na República para 
fortificá-la. Diz a autora: “Assim, o tema da unidade se desloca do campo estritamente nacional para o campo político e social e estrutura-se na mensagem que a instrução escolar veicula".23

Tal afirmação pode ser confirmada através da Lei de Jules Ferry (1832-1893), ministro da Instrução Pública na França na década de 80, que aponta para a separação do Estado e da Igreja no que se refere à escola republicana e retoma a questão da educação moral:

A lei de 28 de março de 1882 se caracteriza por duas disposições que se completam sem contradizer-se: de um lado, deixa fora do programa obrigatório o ensino de qualquer dogma religioso; de outro, põe no primeiro plano o ensino moral e cívico. A instrução religiosa pertence às famílias e à Igreja, a instrução moral à escola. ${ }^{24}$

A laicização do ensino (1882) e a separação da Igreja do Estado (1905), que aconteceram nesse movimento, impulsionaram mudanças nos conteúdos das disciplinas escolares. Q uanto a isso, o historiador francês Ernest Lavisse (1842-1922), do alto de seu posto como professor da Sorbonne, diretor da Escola Normal Superior e diretor da rubrica de história da Revue de Paris, se perguntava:

Qual saber escolar pode mesmo dar aos alunos o sentimento de continuidade da obra humana a não ser ensinando as matérias clássicas e suas mutações que exige adaptação a um mundo transformado e 0 alargamento dos horizontes que incite "deixar às margens do M editerrâneo?" Como melhor conjugar a universal idade da condição humana e a identidade das nações? ${ }^{25}$

Para Hery, Lavisse está sendo muito claro, pois a noção de identidade das nações, o "nós" significa notadamente "nós, franceses", e a disciplina capaz de possi bilitar esse saber, a H istória. Para ela, Lavisse resume "de uma maneira viva a vontade de dar a prioridade às realidades nacionais".

Nora confirma esse trajeto francês ao afirmar que os historiadores da França, principalmente Lavisse e M ichelet, ambos autores de livros didáticos de História, 
[...] estavam imbuídos do sentimento de que seu papel consistia em estabelecer uma memória mais positiva do que as precedentes, mais globalizantes emais explicativas. $O$ arsenal científico do qual a história foi dotada no século passado [XIX] só serviu para reforçar poderosamente 0 estabelecimento crítico de uma memória verdadeira. Todos os grandes remanejamentos históricos consistiram em alargar o campo da memória coletiva. $^{26}$

Verificando as relações entre sentimento nacional eo seu uso como educação cívica, Hery informa quea escola primária, tanto pública como privada, aprendea História da França desde os tempos antigos, de forma a contribuir para enraizar a idéia (a memória) de perenidade da França.

Assim como nos livros de História, esse sentimento era referência também nos livros deleitura. Segundo Petitat, o estudo de M aingueneau ${ }^{27}$ sobre os livros de leitura em uso sob a III República torna mais nítidos os contornos morais e os valores leigos republicanos. Diz Petitat:

Todos eles valorizam o trabal ho e o estudo, atacam a preguiça, honram a bravura do soldado, pedem respeito ao Estado; mas há uma profunda diferença de perspectiva entre os das congregações e os dos republicanos. Os primeiros citam constantemente as principais virtudes, a ordem social e as maravilhas da natureza, relacionando-as à Providência. Em "Joãozinho", protótipo do livro escolar clerical, a evocação dos grandes homens não passa dos personagen s biblícos, das grandes figuras cristãs, dos monarquistas e dos combatentes pela França. Já no "Viagem pela França", cartilha laica por excelência, as alusões a Deus são evitadas; Bossuet e Fenelon são excluídos em 1905; não aparece nenhum rei; a tônica é dada para os sábios, os homens de letras, os administradores e os combatentes ilustres. N enhum dos dois tem a pretensão de seguir passo a passo a história da França; os grandes personagens são a encarnação desta ou daquela virtude; trata-se, simplesmente, de uma coleção histórica de valores exemplares. ${ }^{28}$

É dessa maneira que o ensino de História da França, no ensino primário, une moral e civismo para a transmissão de uma memória nacional. "A França é o mais belo país, sua língua éa mais clara, seus soldados são os mais bravos: ela se reserva um lugar de primeiro plano entre as nações". ${ }^{29}$ 
O estudo histórico da França, no secundário, oficializa-senos programas de ensino no ministério de Salvandy,1837-1839, mas a partir de Victor Duruy e a lei de 16 de abril de 1867, que reorganiza a instrução pública tornando-a obrigatória na escola primária, “é possível adotar uma perspectiva nova, situando a história nacional no seio de uma história universal" 30

A história nacional fornece o sentimento de laços que unem gerações anteriores às gerações presentes e o senso de solidariedade. Estudar a história da França, diz H ery, consiste na narração de uma experiência contínua e coletiva, que na sua herança, a juventude francesa, guarda os meios de sua ação futura, como afirma M onod:

Todos se sentirão os rebentos do mesmo sol, os filhos da mesma raça, de forma alguma renegando parte da herança paternal, todos descendentes da velha França e ao mesmo tempo, cidadãos da França moderna. ${ }^{31}$

A definição nacional do presentechamava imperiosamentesuajustificativa pela iluminação do passado que, no dizer de Nora, toma a seguinte dimensão histórica:

Presente fragilizado pelo traumatismo revolucionário que impunha uma reavaliação global do passado monárquico; fragilizado também pela derrota de 1870 que só tornava mais urgente, com relação à ciência alemã como ao instrutor alemão, o verdadeiro vencedor de Sadowa, o desenvolvimento de uma erudição documentária e da transmissão escolar da memória. Nada se equipara ao tom de responsabilidade nacional do historiador, meio padre, meio soldado: ele manifesta-se, por exemplo, no editorial no primeiro número da Revue historique (1876) onde Gabriel Monod poderia legitimamente ver a "investigação científica, doravante lenta, coletiva e metódica" trabalhar de uma "maneira secreta e segura para a grandeza tanto da pátria quanto do gênero humano".32

Na continuidade, é ainda mais enfático:

Lendo-se um tal texto com cem outros semelhantes, pergunta-se como se pode acreditar na idéia de que a história positivista não era cumulativa. $\mathrm{Na}$ perspectiva finalizada de uma constituição nacional, o político, o mi- 
litar, o bibliográfico e o diplomático são, ao contrário, os pilares da continuidade. A derrota de Azincourt ou o punhal de Ravaillac, o dia dos Dupes ou uma tal cláusula adicional dos tratados de Westphalia sobressaem de uma contabilidade escrupul osa. A erudição a mais aguda soma ou subtrai um detalhe ao capital da nação. Unidade poderosa desse espaço de memória: de nosso berço greco-romano ao império colonial da III República, não mais censura do que entre a alta erudição que anexa ao patrimônio novas conquistas e o manual escolar que impõe a vulgata. ${ }^{33}$

Assim, é pelo conteúdo da história da nação que a memória manteve-se como História. A memória nacional é construída a partir das questões sociais vividas pelos homens que a instituíram e, interpretando sua época, apropriaram-se dos fatos e a erigiram à condição de conhecimento histórico, determinando, sem dúvidas, o conhecimento sobre a história da pátria.

A interpretação desses autores deveu-se, como se viu nos excertos citados, à afirmação dos nacional ismoseuropeuse dos conflitos daí decorrentes. Ou seja, os Estados em organização e estabilização, como a Inglaterra ea França por exemplo, e os Estados ainda em processo de unificação, como a Alemanha e a I tália, vão provocar o interesse pelo estudo de sua história nacional, com preocupação marcadamente ideológica.

Percorrendo o campo da História da educação brasileira que deu origem à H istória do Brasil no século XIX, reconheci o campo institucional da memória que configura os conteúdos a serem ensinados como $H$ istória às crianças no ensino fundamental.

Estudando o substitutivo da reforma educacional de Rui Barbosa no final do século XIX, Souza indica que quanto ao ensino de História, o substitutivo deixava entrever as dificuldades de adaptação do conhecimento histórico ao ensino primário, sendo que o próprio Rui Barbosa confessa sua tendência em defender o ensino dessa disciplina na educação secundária e superior; entretanto "curva-se ao exemplo dos países civilizados onde a história, inseparável do ensino da geografia, fazia parte do ensino das primeiras letras". Sendo assim, a História a ser ensinada na escola primária republicana haveria de ser a História local, tendo a Pátria como núcleo. ${ }^{34}$

Nesse percurso importará recortar a questão para mostrar que 0 cerne do problema de atribuições e finalidades educativas da memória 
como História efetua-se no próprio movimento de institucionalização do Estado Nacional brasileiro.

É consenso egeneralizadamente conhecido quea historiografia do Império teve na constituição do Instituto Histórico e Geográfico Brasileiro (IHGB) o principal, mas não o único centro divulgados de textos históricos, atuando no processo defortalecimento do Estado M onárquico. Fundado com a pretensão de tornar-se arquivo e guardião da história brasileira, estabeleceu diretrizes sobre o que se deveria ou não ser historicizado. Desse processo inicou-se a construção de uma memória da história do Brasil. Entretanto, logo deinício um problema impunha-se. Com a Independência havia-se criado o Estado brasileiro, mas o que seria a Nação diante deum processo separatório da metrópoletão singular como o foi o brasileiro?

É com essa preocupação em escrever uma História nacional, em construir uma nacionalidade luso-brasileira, que se promoveu o concurso para os candidatos que se dispusessem a discutir sobre tão complexa questão: "Como se deve escrever a história do Brasil."

A dissertação de Carlos Frederico P. de Martius, de 1843, foi publicada na revista do Instituto como declaração de que os argumentos contidos no texto do autor eram aceitos e legitimados pela instituição. ${ }^{35}$

A dissertação tratava de indicar ao futuro historiador do Brasil os fatos que deveriam ser levados em conta ao escrever a H istória da Pátria. No tópico I, “I déias Gerais sobrea História do Brasil”, anuncia que quem se encarregar de escrever a História do Brasil:

[...] jamais deverá perder de vista quais os elementos que aí concorrerão para o desenvolvimento do homem. São porém estes el ementos de natureza muito diversa, tendo para a formação do homem convergido de um modo particular três raças, a saber: a de côr de cobre ou americana, a branca ou caucasiana, e enfim a preta ou etiópica. D o encontro, da mescla, das relações mútuas e mudanças dessas três raças, formou-se a atual população, cuja história por isso mesmo tem um cunho muito particular. ${ }^{36}$

Nesses princípios desenvolvidos por M artius enraizar-se-ão as explicações para a formação do povo brasileiro, a saber, na mescla das raças que formaram a população nacional. 
A partir dessas idéias gerais, ele segue informando as relações das três raças com a formação da História do Brasil. Inicialmente trata dos índios (a raça de cor de cobre). Para Martius, o historiador do Brasil deveria:

[...] investigar minuciosamente a vida e as histórias do desenvolvimento aborígenes americanos; e estendendo as suas investigações além do tempo da conquista, prescrutinará a história dos habitantes primitivos do Brasil, história que por ora não dividida em épocas distintas, nem ofere cendo monumentos visíveis, ainda está envolta em obscuridade, mas que por esta mesma razão excita sumamente a nossa curiosidade. ${ }^{37}$

Isso porque:

Só depois de haver estabelecido um juízo certo sôbre a natureza primitiva dos autóctonos brasileiros, poder-seá continuar a mostrar, como se formou o seu estado moral efísico por suas relações com os emigrantes; em queêstes influiram por leisecomércio, ecomunicação, sôbreos índios, e qual a parte que toca os boçais filhos da terra no desenvolvimento das relações sociais dos portuguêses emigrados. ${ }^{38}$

Depoiséa vez do elemento português (decor branca). Estesemostra no centro do descobrimento e desenvolvimento da História do Brasil, na análise de Martius. Ao referir-se ao português, a busca é sempre por mostrar como ocorreram a constituição eo desenvolvimento natural do Brasil, sendo esse elemento o principal veiculador de todo o processo de "descobrimento" do Brasil.

Quando os portuguêses descobriram o Brasil, e nêle se estabeleceram, acharam os indígenas proporcionalmente em tão diminuto número e profundo aviltamento, que nas suas recem-fundadas colônias podiam desenvolver e estender-se quase sem importar-se dos autôctonos. Êstes exerceram sôbre os colonos uma influência negativa tão somente por quanto só os forçaram a acautelar-se contra as invasões hostis, e por isso criaram uma instituição singular de defesa, o Sistema das milícias. [...] vemos que a posição guerreira, em que se colocou o colono português para com o índio, contribuiu muito para a rápida descoberta do interior do país, como igualmente para a extensão do domínio português. ${ }^{39}$ 
Toda a ação do português contribuiu para o processo de descobrimento e colonização primitiva do Brasil. Essa que não pode ser compreendida, segundo o autor, senão em seu nexo com as façanhas marítimas, comerciais eguerreiras dos portugueses, " (...) quede modo al gum pode ser considerado fato isolado na história dêsse povo ativo, e que sua importância e relações com o resto da Europa está na mesma linha com as emprêsas dos portuguêses". Na análise de M artius transparece a idéia de que a História do Brasil deve estar em constante relação com a História Universal:

O historiógrafo do Brasil ver-seá arrastado por tais observações a jamais perder de vista na história da colonização do Brasil, e do seu desenvolvimento civil e legislativo (que acompanhava aquela ao mesmo passo), os movimentos do comércio universal de então, e incorporá-los mais ou menos extensamente à sua história [...]. Assim, por exemplo, está a história do descobrimento do Brasil intimamente ligada com a história comercial de madeira índia chamada japan, que vulgarmente conhecida debaixo do nome de pau brasil, legno brasilo, bresil, etc., foi a causa principal de dar-seà Terra de Santa Cruz o nome de Terra do Brasil. Também a história e movimento mercantil dos metais e pedras preciosas têm as mais estreitas relações com a história do Brasil, e finalmente a das plantas tropicais úteis, conhecidas na Europa depois da descoberta do Novo Mundo, jámais poderá ser separada da história da colonização do Brasil. ${ }^{40}$

Finalmentetrata da "raça africana”. Para o autor da dissertação, sobre como dever-se-ia escrever a História do Brasil, seria importante para o historiador indagar a condição dos negros importados, seus costumes, suas opiniões civis, seus conhecimentos naturais, preconceitos e superstições, os "defeitos e virtudes próprias à sua raça em geral", se quiser demonstrar como tudo reagiu sobre o Brasil.

Sendo a África visitada pelos protuguêses antes da descoberta do Brasil, e tirando êles dêste país grandes vantagens comerciais, éfora de dúvida que já naquele período influia nos costumes o desenvolvimento de Portugal. Por êstemotivo devemos analisar as circunstâncias das colônias portuguêsas na África, de tôdas as quais se trafica em escravatura para o Brasil, deverseá mostrar que movimento imprimiam na indústria, agricultura e o comércio das colônias africanas para com as do Brasil, e vice-versa. ${ }^{41}$ 
Bem fundamentado em fontes criteriosas, o historiador do Brasil deveria investigar todos os fatores sociais, econômicos, climáticos, políticos, geográficos, culturais, da composição do povo brasileiro e, por conseqüência, de sua nacionalidade. Numa palavra:

Nunca por tanto o historiador da Terra de Santa Cruz há de perder de vista que a sua tarefa abrange os mais grandiosos elementos; que não Ihe compete tão somente descrever o desenvolvimento de um só povo, circunscrito em estreitos limites, mas sim de uma nação cuja crise e mescla atuais pertencem à história universal, que ainda se acha no meio de seu desenvolvimento superior. Possa ele não reconhecer em tão singular conjunção de diferentes elementos al gum acontecimento desfavorável, mas sim a conjuntura mais feliz e mais importante no sentido da mais pura filantropia. ${ }^{42}$

Assim, a posição do historiador com sua pátria éo desenvolvimento de uma História, cuja Nação é integrante do universo, que pode difundir sentimentose pensamentos do mais nobre patriotismo. Uma obra histórica, segundo a opinião do autor, deve ter igualmente "a tendência de despertar ereanimar em seus leitores brasileiros amor da pátria, coragem, constância, indústria, fidelidade, prudência, todas as virtudes cívicas". Fazer o povo sentir-se como membros de um país único, como um todo unido. Para isso mostrar as belezas naturais de que o Brasil se compõe e a harmonia das três raças que o sustenta é fundamental.

O Brasil, sendo objeto digno de uma História verdadeiramente popular - no sentido de historicizar a constituição de seu povo - , oferece um feliz estímulo para imprimir à obra desse autor o propósito de construir uma História com todo o zelo patriótico, devendo satisfazer não menos o coração do que a inteligência. E é isso que ocorre com a apropriação dessa dissertação pelos membros do IHGB em seu projeto de construção de uma História Nacional.

Podemos dizer, à guisa de conclusão, que na confluência das análises de Nora \& Le Goff, a H istória do Brasil, em sua gênese e no seu desenvolvimento, nasceu para ser útil à construção deuma memória. Comparativamente ao processo francês, da mesma forma que a História tornava-se um meio importante para dispor da memória nacional. 
A concepção do IH GB sobrea natureza do conhecimento histórico foi determinante na configuração da pesquisa e do ensino (através do Colégio Pedro II) no Brasil. Por esses motivos é que a historiografia do império foi durante muito tempo matriz do estudo das instituições políticas e do discurso fundador da nacionalidade. Dentro dessa característica ideológica, só se podia endossar a consolidação da hegemonia política das elites que projetaram a nação. ${ }^{43}$ Por isso, situar a produção do IH GB relativamente ao que foi seu programa de intervenção cultural e político interessa tanto à crítica das representações que se instituíram como memória como também para a desmontagem dessa memória da nação brasileira no ensino de História.

Esse é um outro ponto importante que quero salientar. As investigações sobre História e Memória no Brasil estão levando a estudos de revisão historiográfica do período imperial. Nesse campo, estão sendo objetos de análises: o IH GB, o Colégio Pedro II, os manuais didáticos utilizados no século XIX e os historiadores do período. ${ }^{44}$ Tal preocupação não somente expande os domínios dessa produção como também reconfigura nos seus métodos e objetos o próprio território em que se vinham movendo as pesquisas sobre a $\mathrm{H}$ istória da disciplina. A convergência de interesses em torno da compreensão da representação e da memória diante do conhecimento histórico, que atualmente se verifica, é exemplo significativo desse processo. A nação parece não ser mais o quadro unitário que encerra a consciência da coletividade, os estudos dos “lugares de memória” revelam essa perspectiva.

Um outro aspecto que vejo como importante nessas investigações éo debate sobre a qualidade da relação História e memória. Ou seja, se elas podem chegar a ser aliadas. E, em caso afirmativo: em que circunstâncias podem sobreviver como tais e em que lugares diferentes assumem posições diferentes.

Acompanhar a apropriação da relação memória e História desses novos estudos é questão de interesse para a História da disciplina, pois permite rastrear os modelos historiográficos inscritos nas suas práticas verificando, por exemplo, como e por que o discurso da nacionalidade voltou-se para as raças formadoras do povo brasileiro, procedimento que tem especial pertinência no caso dos estudos sobre a H istória ensinada no Brasil. 
TOLED O, M aria Aparecida Leopoldino Tursi. History taught under memory empire: discipline history questions. H istória, v. 23 (1-2), p. 13-32, 2004.

A BSTRACT: This work deals with the history taught in initial grades of elementary school, under the perspective of history of disciplines. The text intends to show the current researches contribution about history and memory in order to understand this school discipline trajectory discerning both terms and dealing with their disciplinary courses. It registers that the history taught, mainly in initial grades, was dominantly under the memory empire not only due to the view that history teaching was constructed by dates and national important figures memorization, but also because history became an important mean to dispose memory and change into national History through methodological and historiographic resources from the nineteenth century.

KEYWO R D S: Discipline History; Taught History; History and memory.

\section{NOTAS}

${ }^{1}$ Professora do Departamento de Teoria e Prática da Educação da Universidade Estadual de M aringá - UEM - CEP 87020-900. Doutoranda pelo programa de pósgraduação da PUC-SP. marialeopoldino@pop.com.br

2 BURKE, Peter. História com memória social. In: Variedades de História Cultural. Rio de Janeiro: Civilização brasileira, 2000, p.69.

${ }^{3}$ BURKE, Peter. Op. cit., p.70.

${ }^{4}$ Para uma melhor compreensão dos autores que se dedicaram inicialmente a estudar a problemática da memória ver: FÉLIX, Loiva Otero. História \& M emória - a problemática da pesquisa. Passo Fundo: Ediupf,1998.

${ }^{5}$ N ORA, Pierre. Entre M emória e H istória: a problemática dos lugares. Projeto H istória. São Paulo (n. 10), dez. 1993, p.9.

${ }^{6}$ LE GOFF, Jacques. Memória. In: História e M emória. 4.ed. Campinas: UNICAM P, 1996, p.475.

${ }^{7}$ Estou me referindo principalmente às produções dos anos 1980. Sobre isso ver: CORDEIRO, Jaime Francisco P. A História no centro do debate: as propostas de renovação do ensino de História nas décadas de setenta e oitenta. São Paulo, Araraquara: UNESP, 2000; TOLED O. M aria Aparecida Leopoldino Tursi. 0 professor de 
História e a história ensinada: caminhos de uma discussão. Teoria e Prática da Educação. M aringá: Universidade Estadual de M aringá, v.3(6), p.57-68, 2000.

${ }^{8} \mathrm{O}$ texto de Bittencourt, "As tradições nacionais e o ritual das festas cívicas" (1992) já traz elementos desta discussão.

${ }^{9}$ Sobre essa perspectiva de análise ver: CHERVEL, André. História das disciplinas escolares: reflexões sobre um campo de pesquisa. Teoria \& História, v.2, 1990.

${ }^{10}$ BRUTER, Annie. L 'Histoire Enseignée au Grand Siècle. Belin, 1997.

${ }^{11}$ Para uma mais detal hada análise sobre a retórica ver: M UNAKATA, Kazumi. Por que Descartes criticou os estudos que realizou no Colégio de La Flèche, mesmo admitindo que era "uma das mais célebres escolas da Europa"? PUC-SP. Programa Educação H istória, Política e Sociedade, 2002. Nesse texto o autor traz uma relação de vários autores que tratam da retórica como objeto de estudo.

${ }^{12}$ CHERVEL, André; COM PÈRE, M arie-M adeleine.. As humanidades no ensino. Educação e Pesquisa. FE/U SP, São Paulo, v.25, n.2, jul/dez, 1999, p.155

${ }^{13}$ BRUTER, Annie. Op. cit., p.62.

${ }^{14}$ CO ORN AERT, Emile. D estins de Clio en France depuis de 1800. Paris: Les éditions Ouvrières, 1977, p.95.

${ }^{15}$ Sobre a crise do latim e a emergência da língua francesa ver: CHERVEL, André; COM PĖRE, Marie-M adeleine. Op. cit.

${ }^{16}$ André Petitat trata desta questão no capítulo 5 do texto Produção da Escola, Produção da Sociedade - análise sócio-histórica de alguns momentos decisivos da evolução escolar no ocidente. Porto Alegre: Artes M édicas, 1994. Neste texto tomaremos o exemplo da França.

${ }^{17}$ LOPES, Eliane M. Santos Teixeira. Origens da Educação Pública: a instrução na Revolução Burguesa do século XVIII. São Paulo: Loyola, 1981, p.15.

${ }^{18}$ FURET, François. $O$ nascimento da História. In: A oficina da história. Lisboa: Gradiva, s/d.

${ }^{19}$ Idem, p.127-128, grifo nosso.

${ }^{20}$ HERY, Evelyne. Les enjeux de l'enseignement de I'histoire (1880-1902). In.: Un siècle de leçons d'histoire - I' histoire enseignée au lycée, 1870-1970. Presses Universitaires de Rennes, 1999, p.45, grifo nosso.

${ }^{21}$ Jurista francês que em 1763 publicou Educação Nacional, no qual ele propôs um programa de estudos científicos como substituto para os ensinados pelos jesuítas. 22 apud PETITAT, André. Op. cit., p.141.

${ }^{23}$ HERY, Evelyne. Op. cit., p.71.

${ }^{24}$ FERRY, Jules et alii. La escuela Laica. Buenos Aires: Ed.Losada S.A., 1945, p.14. 
${ }^{25}$ HERY, Evelyne. Op. cit., p.47.

${ }^{26}$ NORA, Pierre. Op. cit., p.10.

27 MAIN GUENEAU, D. Os livros de Escola da República 1870-1914, Paris: Sycomore,1979.

${ }^{28}$ PETITAT, André. Op. cit., p.158.

29 Idem, p. 159.

${ }^{30}$ HERY, Evelyne. Op. cit., p.67.

${ }^{31}$ apud HERY, Evelyne. Op. cit.,p.68.

32 NORA, Pierre. Op. cit., p.11.

33 Idem.

34 SOUZA, Rosa Fátima de. Inovação educacional no século XIX: a construção do currículo da escola primária no Brasil. CEDES, v.20, n.51, Campinas, nov/2000.

35 Para uma melhor compreensão dessa construção pelo IHGB ver: GUIM ARÃES, M anoel Luis Salgado, no texto N ação e Civilização nos trópicos: $O$ Instituto Histórico e Geográfico Brasileiro e o Projeto de uma H istória nacional. Estudos H istóricos, Rio de Janeiro, n.1, 1988.

${ }^{36}$ M ARTIUS, Carlos Frederico Ph. De. Como se deve escrever a H istória do Brasil. Dissertação de 1843. Revista do Instituto H istórico e Geográfico Brasileiro, vol. 219, 1953, p.187.

37 Idem, p. 190.

38 Idem.

39 Idem, p. 194.

40 Idem, p.195-6, grifos no original.

${ }^{41}$ Idem, p.201.

42 Idem, p.201, grifo nosso.

${ }^{43}$ DIAS, M aria Odália L. da Silva. Sociabilidades sem H istórias: Votantes pobres no Império, 1824-1881. In: FREITAS, Marcos Cezar (org.). Historiografia Brasileira em perspectiva. São Paulo: Contexto, 1998.

${ }^{44}$ Referimo-nos aos seguintes trabalhos: ARRUDA, José J. e TENGARRINHA, José M. H istoriografia Luso-Brasileira Conteporânea. São Paulo: EDUSC, 1999; FONSECA, Thais Nívia de Lima (org.). Inaugurando a História e construindo a Nação discursos e imagens no ensino de História. Belo Horizonte: Autêntica, 2001; da mesma autora H istória e Ensino de História. Belo Horizonte: Autêntica, 2003; AN DRADE, Vera Lúcia C. de Queiroz. Colégio Pedro II. Um lugar de memória. Rio de Janeiro, 1999. Tese (Doutorado)-UFRJ, GUIMARÃES, Lucia M aria Paschoal. Debaixo da imediata proteção imperial: o Instituto Historico e Geográfico Brasileiro 
(1838-1889). Revista do Instituto Histórico e Geográfico Brasileiro. Rio de Janeiro, no 388, jul/set. 1988; LACOM BE, Americo Jacobina. A construção da historiografia brasileira: o IHGB e a obra de Varnhagen. RIHGB, Rio de Janeiro, 152(370), jan/ mar. 1991; M ATTOS, Selam Rinaldi. Brasil em lições: a história do ensino de história no Brasil através dos manuais de Joaquim Manuel de M acedo. São Paulo, 1993 Dissertação (M estrado) - Fundação Getúlio Vargas; M ELO, Ciro Bandeira de. Senhores da História: a construção do Brasil em dois manuais didáticos de H istória na Segunda metade do século XIX. São Paulo. Tese (D outorado)-USP; ODÁLIA, Nilo. As formas do mesmo: ensaios sobre o pensamento historiográfico de Varnhagen e OliveiraVianna. São Paulo: UNESP, 1997; GASPARELLO, Arlette M edeiros, Construtores del dentidades: os compêndios dehistória do Brasil do Colégio Pedro II (18381920). São Paulo 2002. Tese (Doutorado)-PUC-SP; DIEHL, Astor Antonio. A cultura historiográfica brasilei ra: do IH GB aos anos de 1930. Passo Fundo: Ediupf, 1998.

Artigo recebido em 09/2003. Aprovado em 03/2004. 